\title{
Teaching innovation and exploration of the core course construction for postgraduates of electromechanical system dynamics
}

\author{
Qiao-yi WANG ${ }^{1, a}$, Yuan ZHU ${ }^{1, b}$, Shan GUO ${ }^{1, c}$ \\ ${ }^{1}$ School of Mechanical engineering, Hangzhou Dianzi University, Hangzhou 310018, China \\ a'wangqiaoyi1989@163.com, bzhuyuan_Zoe@163.com, 'ouoshan1990@163.com
}

\begin{abstract}
Keywords: Electromechanical system dynamics; core course for postgraduates; teaching innovation; the method of case teaching

Abstract. Electromechanical system dynamics is a specialized course for postgraduates with a close combination with basic theory and practice. It is a interdisciplinary subject of mechanism and mechanical engineering, containing the high abstraction and rigorous science of the basic theory and the universality and applicability of practice. In this paper, to improve postgraduates' interests and desire to participate in practical subject, the contents and teaching mode of electromechanical system dynamics are innovated, the method of case teaching is introduced, means of assessment are reformed and students are leaded to discover and raise new problems from actual phenomenon. Therefore students are able to master problem-solving methods and apply them to their own research projects and some achievements are made during the practice of cultivating 'research-type' students.
\end{abstract}

\section{Introduction}

Electromechanical system dynamics, lecturing on the basic theories and methods of mechanical system dynamics modeling and analysis, is an important professional basic course for postgraduates majoring in Mechanical Engineering. Aiming at cultivating students' abilities to adapt themselves to scientific research in the future, it has always been a key course for postgraduates in Mechanical Engineering. Through the course, students will have an exact basic concept of mechanical system dynamics modeling and analysis, necessary professional knowledge and analytical and calculating capability. Electromechanical system dynamics in most college contains the theory of vibration analysis of mechanical system dispersion model, dynamic analysis theory and method of mechanical elastomer system, dynamic analysis of typical mechanism and numerical solution and simulation of mechanical system dynamics problems.

Electromechanical system dynamics core course for postgraduates is a professional compulsory subject in School of mechanical engineering of Hangzhou Dianzi University. Just like any other courses, it has only 48 hours but contents is comprehensive and complex. As a result, in order to improve teaching quality, traditional Chinese education like only imparting knowledge must be changed and the educating concept of integrating teaching knowledge, cultivating abilities and enhancing quality must be established. Through the classroom instruction, the method of case teaching, discussion, course project, site visits and experimental proof, students' abilities like self-study, manipulation, innovation, and identifying problems, analyzing problems and solving problems should be cultivated. At the same time, faced with teaching objects of different administrative levels, teaching methods should be different, so that students' enthusiasm and initiative will be promoted. Then in order to improve students' ability of acquiring knowledge, it's 
also necessary to update teaching methods, to increase contents and to improve teaching effect. At present, the teaching methods of this course have following problems:

(1) Because of the different levels of freshmen, some of whom are not familiar with vibration theory and even don't know it before, the basic theory is hard to convey.

(2) When it comes to system dynamic analysis and numerical solution, a large number of mathematical formulations are involved which are abstract and complex.

(3) Contents are obsolete, lack of new relevant knowledge, most of which overlap with theory of mechanical vibration in the old syllabus.

If students are taught in a traditional mode, at the end of the course, students can only command basic dynamic concept and can only model and analyze by commercial software. it's difficult for them to establish a clear view of system dynamics. In this way, it's far from the object 'cultivate the ability of abstracting specific engineering problems as dynamics, and then solve them with dynamic methods '.This course is in an urgent need to introduce a new knowledge system, to adopt a new teaching mode and to introduce new assessment methods.

\section{Modularization of Course Content}

Course content is the main basis of teacher's lecture and the important goal of students. It's very significant to meet and even be beyond the requirements outlined in the syllabus for students which is helpful to summarize teaching experience, to improve teaching quality for teachers and to study and development for students. Electromechanical system dynamics is open to postgraduates whose major is Mechatronic Engineering, Mechanical Design and theory or Mechanical Manufacture and Automation. Some of published books are too theoretical, some focus too much on thematic analysis and others are comprehensive, obscure and unreadable. In view of the situation, it's necessary to carry out research on teaching content and method and establish a scientific system. For this purpose, on the basis of comprehending domestic and foreign works, teaching practice and summarized experience are combined and teaching contents and methods are improved to establish a new content system which meets the teaching requirement and reflects the development of Electromechanical system dynamics. The new content system has the following characteristics: modeling is integrated with simulation, control theory, electromechanics and dynamics; what lecture notes convey are clear and easy to understand and are suitable for current course schedule; by linking practice with theory, students' abilities of analyzing and solving problems and innovating are trained.

\section{Flexibility of Teaching Method}

Heuristic teaching should totally take the place of the traditional 'cramming' teaching method. And most attention should be paid to cultivating students' ability of self-study and the ability of identifying, analyzing and solving problems. Some adjustments should be made to contents and students should be taught in a progressive and emphatic way according to degree of importance and difficulty of chapters.

At present, postgraduates put more emphasis on practicality of the curriculum and they hope to improve themselves through concrete projects so that they can put what they learn into practice, which require the teacher to provide practical teaching cases and scientific research platform.

In order to offer students chances to take part in scientific research and to help them lay a solid foundation for future development, group research activities should be carried out and subtopics in the project given by the teacher should be discussed during the lecture. In this way, this course will 
be popular among students and some achievements will be made in teaching effects.

During the lecture, in addition to focusing on the practice, it's important to emphasize students' subjectivity and good classroom atmosphere. The precision of basic concepts and principles and the engineering application that needs divergent thinking have become the obvious feature of this course.

\section{Speciality of Case Teaching}

Because of the teaching object, the course should be taught by special lecture, where teachers are expected to interact with students, simulate students' interest in learning and promote students' creative thinking. In the course, some inconclusive problems should be introduced, which gives students large space to study and think.

By introducing a large amount of professors' achievements during case teaching, students will be encouraged and will make some progress. In the analysis of vehicle system dynamics, some questions are raised. For example, why did the car crash, why do some people have carsickness, why does the vibration increase after vehicle increasing its speed, where is the most comfortable place when you take bus. For better interaction, we interest students by introducing everyday experience into the research of vehicle dynamics. When teaching vehicle driving dynamics and vehicle steering dynamics, professor's research project is combined and the latest research results of vehicle dynamics are introduced into lecture. In this way, students will have a better command of actual application of kinetic theory in vehicles. In addition, to deepen students' understanding of relevant knowledge points, students are showed the vehicle engineering laboratory. By making full use of equipments in the laboratory, the origin, phenomenon and solution of vehicle dynamics will be expressed in detail. Also, the teacher should raise some specific questions after visit and comment on the scene in terms of students' answers. This pattern of teaching is popular with students, leaving a refreshing feeling.

In addition, an unavoidable problem in the course is that the requirement of mathematics is higher. To avoid complex formula derivation, the connection of knowledge points in the lecture should be paid to attention, forming a divergent knowledge network. The lecture often starts from familiar and objective background where the contents are put in. For example, when lecturing the dynamics of nonlinear systems, to avoid the derivation of complicated mathematical formulas and laws of mechanics, by introducing cases of vibration in mechanical industry, the project of 'modeling and simulation of mill system dynamics' is set up, where basic concepts and analyzing methods of nonlinear system dynamics are integrated and dynamics of main drive system of electromechanical coupling mill under the influence of nonlinear factors is analyzed. This course not only emphasizes the modeling, solution and analysis of actual project, but also focuses on basic theory and analyzing method, which enable students to use what they learn into research.

\section{Diversity of Assessment Form}

Diversity of assessment form can effectively promote students' innovation ability. Instead of separating of teaching and testing, we focus on students' abilities of understanding, mastery and flexibility of theoretical knowledge. Test paper examination or course project are taken place by a combination of various assessment method. Test paper examination, judging students by only one test, is too one-sided to verify the degree of knowledge students command. Also simple course project can't reflect the degree of mastery of learning method. Those who make up a number without active work will drain others' enthusiasm. Therefore the following 3 ways are used to 
assess students' final results:

(1) Course project assessment

Students choose one from several projects given by the teacher, which requires to be finished in combination with tutor's research direction. By doing so, students will lay solid foundation for subject research.

(2) Course assignment assessment

The teacher assign homework after completing a module. In order to reduce the difficulty when students finish their homework, online tutoring and online Q\&A sessions are provided.

(3) Literature review report

At the end of the course, a literature review report is held to talk about contents of minimum of 5 references literature concerning their own course project. Also the teacher and other students can raise some questions after addressing. At last, grades are given.

\section{Conclusion}

How to systematically and effectively impart knowledge to students and how to help students master knowledge and skills is an extremely serious problem that should be taken into consideration by each teacher.

Electromechanical system dynamics core course for postgraduates should make more efforts in teaching content, teaching link arrangement, teaching method improvement and teaching effect assessment to make improvement continuously according to its features. What's more, the key step to innovate is that the contradiction between comprehensive contents and limited time and the contradiction between practical teaching and theoretical teaching should be solved.

\section{Acknowledgement}

This research was financially supported by the core course construction for postgraduates of electromechanical system dynamics in Hangzhou Dianzi University (HXKC2016019).

\section{References}

[1] HAN Qingkai, YU Tao, SUN Wei. Modern dynamic design and analysis of mechanical vibration system[M]. Beijing: Science Press, 2010.

[2] SHI Hanmin, HUANG Qibo. Mechanical vibration system: analysis modeling testing countermeasure[M]. Wuhan: Huazhong University of Science and Technology Press, 2013.

[3] LI Youtang. Mechanical system dynamics[M]. Beijing: National Defense of Industry Press,2010.

[4] JIANG Wei, SUN Yuehua, HOU Qingquan, XU Peng. Reform and practice of teaching contents of ‘mechanical vibration theory'[J]. Education Teaching BBS, 2015(40):99-100.

[5] HE Zhixian. Mechanical system dynamics[M]. Xian: Xidian University Press,2017.

[6] CUI Yuxin. Mechanical system dynamics[M]. Beijing: Science Press, 2017.

[7] CHEN Huitao, CHAI Shanshan, YANG Zhibo. Study on teaching mode reform of mechanical vibration course to postgraduate[J]. China Educational Technique \& Equipment,2017(416):107-108. 